J. Lake Sci. (湖泊科学), 2015, 27(2):234-242

http: //www. jlakes. org. E-mail : jlakes@niglas.ac.cn

(c) 2015 by Journal of Lake Sciences

\title{
水生植被恢复对城市景观水体磷浓度及沉积物磷形态的影响”
}

\author{
琚泽文 ${ }^{1}$, 蔚枝沁 ${ }^{4}$, 邓 泓 ${ }^{1,2,3 * *}$ \\ (1: 华东师范大学生态与环境科学学院, 上海 200241) \\ ( 2 : 华东师范大学上海市城市化生态过程与生态恢复重点实验室, 上海 200241) \\ (3: 华东师范大学浙江天童森林生态系统国家野外科学观测研究站, 上海 200241) \\ ( 4 : 重庆市合川区环境监察支队, 重庆 401520 )
}

\begin{abstract}
摘 要: 以上海市两个水生植被恢复时间为 5-10 年的城市景观水体为研究对象, 通过分析水体理化性质以及水和沉积 物磷的含量和形态, 研究水生植被恢复对富营养化水体修复的长期生态效应. 结果表明, 水生植被恢复能有效降低水体 氮、磷浓度, 对水体富营养化有明显的改善作用. 在外源磷的污染源得到控制后, 水体磷浓度会随着修复时间的增加而逐 渐降低并相对稳定. 沉积物磷形态以钙磷为主, 随着水生植被恢复时间的增加, 生物活性较强的可交换态磷、铝磷和铁磷 的含量下降, 而相对稳定的钲磷所占的比例增加. 研究结果还表明, 即使不进行底泥疏浚, 长期的水生植被恢复也可以使 城市河流沉积物中内源磷释放及水体磷浓度得到有效控制.
\end{abstract}

关键词 : 水生植物;恢复;沉积物; 磷形态; 释放;丽娃河; 曹杨环浜

\section{Effects of aquatic vegetation rehabilitation on phosphorus in water and sediments of ur- ban landscape waters}

\section{JU Zewen ${ }^{1}$, YU Zhiqin ${ }^{4} \&$ DENG Hong ${ }^{1,2,3}$}

(1: School of Ecological and Environmental Science, East China Normal University, Shanghai 200241, P. R. China)

(2: Shanghai Key Lab for Urban Ecological Processes and Eco-Restoration, East China Normal University, Shanghai 200241, P. R. China)

(3: Tiantong National Station of Forest Ecosystem, East China Normal University, Shanghai 200241, P. R. China)

(4: Environmental Monitoring Team of Hechuan Chongqing, Chongqing 401520, P. R. China)

\begin{abstract}
The paper was conducted to investigate the long term effects of aquatic vegetation rehabilitation on phosphorus in eutrophicated urban landscape waters. The results indicated that aquatic vegetation rehabilitation could effectively reduce the level of nitrogen and phosphorus in water and the eutrophication. With the control of external source, phosphorus concentration in water decreased till it reached a relatively stable state. By analysis of $\mathrm{P}$ fraction, Ca-P was found to be the main fraction in sediment and increased while the ratios of Ex-P, Al-P and Fe-P, which are considered more bioavailable than Ca-P, decreased with vegetation rehabilitation time. It's also indicated that long term aquatic vegetation rehabilitation was possible to effectively immobilize internal sediment $\mathrm{P}$ and reduce its release to water in Caoyang River, even without dredging activity.
\end{abstract}

Keywords: Hydrophyte; restoration; sediment; phosphorus fractions; release; Liwa River; Caoyang River

城市水体是城市工业及生活用水的主要水源,也是城市景观的一个重要组成部分, 被称为城市生态系 统的“血液”, 影响着城市居民生活质量, 是城市生态评价的一个重要指标 ${ }^{[1]}$. 然而, 在城市化过程中由于人 口聚集, 大量工业废水和生活污水不合理排放, 向水体中输人了大量营养盐, 特别是磷的过量输人, 使城市 水体富营养化程度加剧. 城市水体的富营养化, 甚至黑臭,已经对城市居民的正常生活造成严重影响, 城市

* 上海市自然科学基金项目 (08ZR1406800)资助. 2014-03-17 收稿;2014-06-24 收修改稿. 琚泽文(1989～),男, 硕士研究生;E-mail: juzewen97@ sina. com.

** 通信作者;E-mail:hdeng@ des. ecnu. edu. cn. 
水体富营养化开始受到人们的重视. 很多城市开始控制污水排放, 对水体进行综合治理, 例如, 上海市早在 1980s 初就已经开始了城市富营养化水体的治理, 并取得一定成效. 然而, 研究表明, 在外源磷的输人得到有 效控制后, 沉积物中内源磷的释放仍能使水体富营养化状态持续数十年 ${ }^{[2-3]}$.

水生植物是水生生态系统的重要组成部分, 介于底泥一水体一空气之间, 对生态系统物质和能量的循环 传递起调控作用 ${ }^{[4]}$. 利用水生植物启动并构建良性循环的水生生态系统正逐渐成为浅水湖泊、河流的最主 要修复措施 ${ }^{[5-9]}$. 然而, 对城市河道富营养化景观水体生态修复的长期生态效果却少有研究. 本文以上海市 两条经过 5-10 年水生植被恢复的城市景观水体为研究对象, 分析水质及沉积物磷素含量和形态, 以研究 水生植被恢复的长期生态效应及修复机制, 为城市水体生态修复提供进一步的科学依据.

\section{1 材料与方法}

\section{1 研究区域概况}

本文选取上海市普陀区两条景观水体作为研究对象. 其中, 丽娃河 $\left(31^{\circ} 13^{\prime} \mathrm{N}, 121^{\circ} 24^{\prime} \mathrm{E}\right)$ 位于华东师范 大学普陀校区内, 曾是苏州河的支流. 1980s 开始, 由于生活污水、地表径流雨水的大量排放, 水体营养负荷 日趋增加, 多次暴发水华, 属于严重的典型富营养化污染城市水体. 2003 年水体营养盐及耗氧性有机物均超 过地表水 $\mathrm{V}$ 类标准数倍, 其中总氮 $(\mathrm{TN})$ 浓度最高达到 $26.76 \mathrm{mg} / \mathrm{L}$, 铵态氮 $\left(\mathrm{NH}_{4}^{+}-\mathrm{N}\right)$ 平均浓度达到 $7.57 \mathrm{mg} / \mathrm{L}$, 总磷 ( TP) 平均浓度达到 $1.13 \mathrm{mg} / \mathrm{L}$, 最高可达 $2.17 \mathrm{mg} / \mathrm{L}$, 化学需氧量 (COD) 也达到了 $58.9 \mathrm{mg} / \mathrm{L}^{[10]} .2004$ 年丽娃河进行了截污、清淤、景观等一系列综合整治, 并于 2005 年开始进行水生植被恢 复, 在之后的 5 年内, 水生植物生长良好, 优势种以荷花 (Nelumbo nucifera)、睡莲 (Nymphaea tetragona Georgi) 等浮叶植物和菹草 (Potamogeton crispus L.) 、苦草(Vallisneria natans (Lour.) Hara) 等沉水植物为主. 曹杨 环浜 $\left(31^{\circ} 14^{\prime} \mathrm{N}, 121^{\circ} 24^{\prime} \mathrm{E}\right)$ 在地理位置上与丽娃河邻近, 历史上与丽娃河同属苏州河同一支流, 后经过截流 形成环形封闭河道, 周边的环境特征与丽娃河十分相近. 曹杨环浜周围楼房林立, 居住着 10 多万居民, 人口 密度和建筑密度极高, 由于大量城市污水和垃圾注人, 河水富营养化严重, 水体 TN、TP、COD、BOD 5 等指标均 超过了劣 V 类水质标准, 水体发黑发臭严重 ${ }^{[11]}$, 在进行水生植被恢复之前, 河流水质和沉积物的污染状况与丽 娃河极为相似, 均属于重度富营养化的典型黑臭水体. 该河流于 $1980 \mathrm{~s}$ 初进行截污治理, 1990s 开始通过重建水 生植被净化水质, 是上海市最早一批开展生态修复的城市水体, 并于 2003 年进一步扩大了水生植物的种植面 积. 截至本研究, 曹杨环浜的水生植被恢复时间约为 10 年, 优势种为苦草、金鱼藻 (Ceratophyllum demersum L. )、黑藻 (Hydrilla verticillata) 、菹草、睡莲及黄菖蒲 (Iris pseudacorus L.) 等. 与丽娃河不同的是, 曹杨环浜在生 态恢复的过程中始终没有进行清淤, 即直接通过水位调节后在原有的底质上进行水生植被恢复.

\section{2 研究方法}

根据丽娃河和曹杨环浜周边环境 和水体植被生长状况, 在有代表性的河 段设置样点, 其中丽娃河 8 个, 曹杨环 浜 9 个 (图 1). 丽娃河 2008 年秋季水 生植物全部被清除, 以至于当年冬季采 样的时候未发现植物. 曹杨环浜则在 2009 年夏季采样时部分植物被清除. 按季度用沉积物柱状采泥器( SEDIMENT CORER, 德国 HYDRO-BIOS) 在 各样点分层采集沉积物, 采样柱中靠近 柱顶水土界面 $0 \sim 10 \mathrm{~cm}$ 的沉积物记为 上层; 柱底远离水土界面的底部沉积物 (10 cm 以上) 记为下层. 沉积物带回实 验室, 先用土壤溶液提取器提取间隙 水, 用比色法测定溶解性无机磷

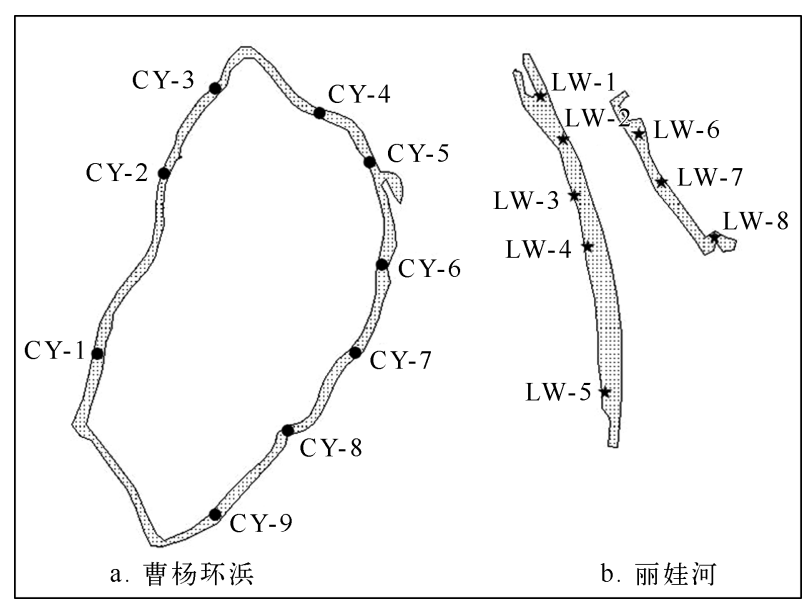

图 1 曹杨环浜和丽娃河的相对地理位置

Fig. 1 Sampling sites of the Caoyang River and Liwa River 
(DIP), 后经冷冻干燥后采用连续提取法 ${ }^{[12]}$ 逐级提取可交换态磷 ( Ex-P)、铝磷 ( Al-P)、铁磷 $(\mathrm{Fe}-\mathrm{P})$ 、钙磷 ( Ca-P)、蓄闭态磷 $(\mathrm{OcP})$ 、有机磷 $(\mathrm{Or}-\mathrm{P})$.

两条河流的水质取样分析于 2008-2011 年进行. 丽娃河在每个样点用采水器取水面以下 $10 \mathrm{~cm}$ 的水样 作为表层水,柱状采泥器采样管中沉积物的上覆水作为下层水. 曹杨环浜由于水位较浅,仅采集了表层水. 采用纳氏试剂比色法测定水体 $\mathrm{NH}_{4}^{+}-\mathrm{N}$, 水样过 $0.45 \mu \mathrm{m}$ 滤膜后用钼酸铵比色法测定 DIP, 用碱性过硫酸钾 氧化法测定水体 $\mathrm{TN}$ 和 $\mathrm{TP}^{[13]}$. 同时, 详细记录不同季节每个样点附近的水质状况, 包括水温、 $\mathrm{pH}$ 、溶解氧 (DO) 和植被生长情况等.

\section{2 结果与分析}

\section{1 水生植被恢复后河流水质变化情况}

经过较长时期的植被恢复, 丽娃河和曹杨环浜的水质得到有效改善, 水体 N、P 营养元素的浓度控制在 相对稳定的水平. 丽娃河水体 $\mathrm{TN}$ 浓度在 $1.24 \sim 2.11 \mathrm{mg} / \mathrm{L}$ 之间; $\mathrm{NH}_{4}^{+}-\mathrm{N}$ 的平均浓度为 $0.77 \mathrm{mg} / \mathrm{L}$, 并随修 复时间的增加呈下降趋势; TP 浓度为 $0.08 \sim 0.29 \mathrm{mg} / \mathrm{L}$, 水质达到 I 类 IV 类水质标准 (表 1 ) ; DIP 浓度为 $0.01 \sim 0.25 \mathrm{mg} / \mathrm{L}, \mathrm{pH}$ 介于 $7.5 \sim 8.3$ 之间. 水温变化范围为 $7.43 \sim 28.33^{\circ} \mathrm{C}$, 季节变化明显; DO 含量较高, 为 $6.20 \sim 9.04 \mathrm{mg} / \mathrm{L}$. 李静文等 ${ }^{[14]} 2007$ 年对丽娃河水体 $\mathrm{COD}_{\mathrm{Cr}}$ 的监测结果显示, 水体 $\mathrm{COD}$ 从修复前的 $58.9 \mathrm{mg} / \mathrm{L}$ 降低到 $21.5 \mathrm{mg} / \mathrm{L}$, 丽娃河的水生植被恢复初见成效. 曹杨环浜在经过长期水生植被恢复之后, 水 体 $\mathrm{TN}$ 平均浓度为 $1.53 \mathrm{mg} / \mathrm{L}$, 最低为 $1.11 \mathrm{mg} / \mathrm{L} ; \mathrm{NH}_{4}^{+}-\mathrm{N}$ 的浓度为 $0.32 \sim 0.69 \mathrm{mg} / \mathrm{L}$; $\mathrm{TP}$ 浓度在 $0.04 \sim$ $0.23 \mathrm{mg} / \mathrm{L}$ 之间; DIP 浓度为 $0.01 \sim 0.06 \mathrm{mg} / \mathrm{L} ; \mathrm{pH}$ 值为 $8.0 \sim 8.7$; 水温为 $6.83 \sim 26.34^{\circ} \mathrm{C}$, 平均比丽娃河水 温低 $2^{\circ} \mathrm{C}$; DO 含量为 $7.19 \sim 9.72 \mathrm{mg} / \mathrm{L}$.

两条河的富营养化水质随季节变化明显. 水体 $\mathrm{TN}$ 浓度随季节变化波动较大, 没有明显的季节变化规 律. 而水体 TP 浓度呈现一定的季节变化规律. 在温度较低的冬季( 丽娃河平均水温 $7.4^{\circ} \mathrm{C}$, 曹杨环浜 $6.8^{\circ} \mathrm{C}$ ), 曹杨环浜和丽娃河的水体 TP 和 DIP 浓度均达到最低值 ( TP $<0.1 \mathrm{mg} / \mathrm{L} 、 \mathrm{DIP}<0.05 \mathrm{mg} / \mathrm{L})$. 随着温度的升高, 水体 $\mathrm{TP}$ 浓度增加, 夏季 (丽娃河平均水温 $28.3^{\circ} \mathrm{C}$, 曹杨环浜 $26.3^{\circ} \mathrm{C}$ ) 达到最大值, 水体 $\mathrm{TP}$ 浓度与水温在 0.05 水平上呈显著正相关. 与水体 $\mathrm{TP}$ 季节变化不同的是, 春季 DIP 浓度随水温升高不明显, 其中丽娃河水 体 DIP 浓度在春季反而降低, 可能是由于春季水生植物大量萌发生长, 吸收水中的 DIP, 从而使其浓度降低.

表 1 丽娃河和曹杨环浜历年水体理化参数变化

Tab. 1 Variation of physical and chemical parameters in Liwa River and Caoyang River

\begin{tabular}{ccccccccc}
\hline 河流 & 时间 & $\mathrm{TN} /(\mathrm{mg} / \mathrm{L})$ & $\mathrm{NH}_{4}^{+}-\mathrm{N} /(\mathrm{mg} / \mathrm{L})$ & $\mathrm{TP} /(\mathrm{mg} / \mathrm{L})$ & $\mathrm{DIP} /(\mathrm{mg} / \mathrm{L})$ & $\mathrm{pH}$ & $\mathrm{T} /{ }^{\circ} \mathrm{C}$ & $\mathrm{DO} /(\mathrm{mg} / \mathrm{L})$ \\
\hline 丽娃河 & $2008-10$ & $1.82 \pm 0.18$ & $0.95 \pm 0.31$ & $0.19 \pm 0.02$ & $0.05 \pm 0.03$ & 7.5 & 19.06 & 7.29 \\
& $2008-12$ & $1.86 \pm 0.39$ & $1.06 \pm 0.26$ & $0.08 \pm 0.04$ & $0.04 \pm 0.02$ & 8.3 & 7.43 & 7.18 \\
& $2009-04$ & $2.11 \pm 0.47$ & $0.88 \pm 0.20$ & $0.12 \pm 0.02$ & $0.02 \pm 0.01$ & 8.0 & 14.18 & 8.38 \\
& $2009-06$ & $1.27 \pm 0.19$ & $0.78 \pm 0.08$ & $0.22 \pm 0.03$ & $0.17 \pm 0.03$ & 7.8 & 19.25 & 8.60 \\
& $2009-08$ & $1.82 \pm 0.24$ & $0.86 \pm 0.24$ & $0.29 \pm 0.11$ & $0.10 \pm 0.04$ & 7.6 & 28.33 & 9.04 \\
& $2010-09$ & $1.24 \pm 0.53$ & $0.63 \pm 0.34$ & $0.28 \pm 0.07$ & $0.25 \pm 0.06$ & 7.9 & 26.84 & 8.32 \\
& $2010-12$ & $1.73 \pm 0.26$ & $0.42 \pm 0.12$ & $0.09 \pm 0.02$ & $0.02 \pm 0.01$ & 8.2 & 8.37 & 6.20 \\
& $2011-04$ & $1.42 \pm 0.30$ & $0.54 \pm 0.31$ & $0.23 \pm 0.01$ & $0.01 \pm 0.00$ & 8.1 & 15.43 & 8.37 \\
曹杨环浜 & $2009-04$ & $1.50 \pm 0.29$ & $0.60 \pm 0.12$ & $0.08 \pm 0.04$ & $0.03 \pm 0.02$ & 8.4 & 19.08 & 8.84 \\
& $2009-08$ & $1.66 \pm 0.26$ & $0.69 \pm 0.23$ & $0.23 \pm 0.05$ & $0.16 \pm 0.05$ & 8.0 & 26.34 & 9.72 \\
& $2010-01$ & $1.99 \pm 0.76$ & $0.32 \pm 0.09$ & $0.08 \pm 0.02$ & $0.02 \pm 0.01$ & 8.6 & 6.83 & 7.33 \\
& $2010-09$ & $1.60 \pm 0.33$ & $0.36 \pm 0.05$ & $0.14 \pm 0.02$ & $0.12 \pm 0.01$ & 8.1 & 24.41 & 8.96 \\
& $2010-12$ & $1.51 \pm 0.03$ & $0.43 \pm 0.07$ & $0.04 \pm 0.00$ & $0.01 \pm 0.00$ & 8.7 & 8.19 & 7.19 \\
& $2011-04$ & $1.11 \pm 0.13$ & $0.51 \pm 0.19$ & $0.15 \pm 0.02$ & $0.06 \pm 0.02$ & 8.3 & 15.33 & 8.64 \\
\hline
\end{tabular}

对两条河流同时期 (2009 年 4 月-2011 年 4 月) 水质进行分析比较发现,丽娃河水体 $\mathrm{TP}$ 和 $\mathrm{NH}_{4}^{+}-\mathrm{N}$ 浓度 都显著大于曹杨环浜水体; DO 含量明显低于曹杨环浜; TN 浓度波动较大, 两条河流同时期 TN 浓度没有明 
显差异. 对比两条河流在季节交替时水体 TP 浓度还发现, 在 2010 年 12 月至 2011 年 4 月, 水温回升, 曹杨环 浜水体 TP 浓度的起伏波动明显小于丽娃河. 这说明, 磷的浓度随着恢复时间的增加明显降低, 并且在季节 交替等外界环境变化的情况下水体更加稳定. 利用水生植物启动并构建良性循环的水生生态系统对富营养 化水体修复作用显著, 并且能够长期有效地控制城市水体富营养化水平.

\section{2 水生植被恢复对沉积物磷形态的影响}

2.2 .1 沉积物磷形态组成及季节变化 丽娃河、曹杨环浜沉积物中各形态的 P 含量如表 2 所示. 各形态的 $\mathrm{P}$ 含量主要为 Ca-P $>\mathrm{OcP}>\mathrm{Fe}-\mathrm{P} 、 \mathrm{Or}-\mathrm{P}>\mathrm{Ex}-\mathrm{P}>\mathrm{Al}-\mathrm{P}$. 绝大部分样点沉积物中 P 主要以 Ca-P 形式存在: 丽娃河 上层沉积物 Ca-P 含量占所有形态磷含量的 31. 66\% 74. 08\%, 下层为 34.80\% 67. 15\% ; 曹杨环浜上层沉积 物 Ca-P 含量占所有形态磷含量的 $61.95 \% \sim 83.38 \%$, 下层为 $47.58 \% \sim 87.82 \%$. 其次是 OcP, 其中丽娃河沉 积物中 OcP 含量较高, 约占所有形态磷含量的 $31.45 \%$ (上层) 和 $43.82 \%$ (下层). Ex-P 与 Al-P 在沉积物中 含量最低.

表 2 丽娃河和曹杨环浜水体沉积物中各形态磷的含量 $(\mathrm{mg} / \mathrm{kg})$

Tab. 2 Contents of different phosphorus fractions in sediments in Liwa River and Caoyang River $(\mathrm{mg} / \mathrm{kg}$ )

\begin{tabular}{|c|c|c|c|c|c|c|c|c|}
\hline 河流 & 季节 & 层次 & Ex-P & Al-P & Fe-P & Ca-P & $0 c \mathrm{P}$ & Or-P \\
\hline \multirow[t]{8}{*}{ 丽娃河 } & 2008 年秋 & 上层 & $18.30 \pm 1.877$ & $15.91 \pm 4.587$ & $64.44 \pm 90.66$ & $566.6 \pm 88.65$ & - & - \\
\hline & & 下层 & $17.34 \pm 2.068$ & $6.995 \pm 2.931$ & $44.46 \pm 46.53$ & $502.1 \pm 47.63$ & - & - \\
\hline & 2008 年冬 & 上层 & $24.95 \pm 3.397$ & $12.51 \pm 7.664$ & $80.54 \pm 79.74$ & $643.0 \pm 64.62$ & - & - \\
\hline & & 下层 & $24.68 \pm 1.396$ & $17.17 \pm 16.75$ & $73.14 \pm 63.28$ & $648.4 \pm 145.1$ & - & - \\
\hline & 2009 年春 & 上层 & $11.29 \pm 2.431$ & $0.732 \pm 0.246$ & $104.2 \pm 99.21$ & $669.8 \pm 203.2$ & $378.1 \pm 470.0$ & $76.06 \pm 21.03$ \\
\hline & & 下层 & $6.151 \pm 3.431$ & $0.900 \pm 0.361$ & $98.03 \pm 63.18$ & $597.4 \pm 89.82$ & $597.3 \pm 208.3$ & $44.58 \pm 5.313$ \\
\hline & 2009 年夏 & 上层 & $7.141 \pm 4.293$ & $1.082 \pm 0.459$ & $139.6 \pm 82.49$ & $628.0 \pm 148.6$ & $523.4 \pm 287.9$ & $55.49 \pm 17.65$ \\
\hline & & 下层 & $9.563 \pm 1.702$ & $0.714 \pm 0.265$ & $115.1 \pm 71.52$ & $582.2 \pm 72.20$ & $618.8 \pm 228.1$ & $57.47 \pm 14.45$ \\
\hline \multirow[t]{6}{*}{ 曹杨环浜 } & 2009 年春 & 上层 & $8.404 \pm 3.617$ & $1.499 \pm 1.373$ & $42.32 \pm 21.62$ & $684.0 \pm 87.24$ & $47.40 \pm 24.65$ & $132.2 \pm 46.66$ \\
\hline & & 下层 & $2.176 \pm 0.906$ & $0.604 \pm 0.293$ & $15.26 \pm 5.782$ & $789.3 \pm 293.4$ & $40.61 \pm 29.55$ & $72.10 \pm 21.51$ \\
\hline & 2009 年夏 & 上层 & $6.830 \pm 4.588$ & $1.597 \pm 0.665$ & $38.11 \pm 25.42$ & $707.5 \pm 62.20$ & $78.59 \pm 32.26$ & $160.8 \pm 57.41$ \\
\hline & & 下层 & $2.026 \pm 1.190$ & $1.126 \pm 0.350$ & $17.45 \pm 17.62$ & $698.3 \pm 67.02$ & $53.15 \pm 24.20$ & $86.89 \pm 20.35$ \\
\hline & 2010 年冬 & 上层 & $12.81 \pm 3.469$ & $0.601 \pm 0.452$ & $24.00 \pm 19.58$ & $763.3 \pm 87.61$ & $86.86 \pm 31.50$ & $172.1 \pm 56.48$ \\
\hline & & 下层 & $4.643 \pm 2.574$ & $1.032 \pm 0.710$ & $35.17 \pm 54.60$ & $862.1 \pm 306.2$ & $70.51 \pm 20.54$ & $90.82 \pm 10.06$ \\
\hline
\end{tabular}

结果显示, 两条河流表层沉积物中 Fe-P、Ex-P 与 Al-P 含量随季节变化明显. 冬季 Ex-P 含量明显高于 春、夏季, 丽娃河沉积物 Al-P 也有类似变化; 而上层沉积物中 Fe-P 的含量则是春、夏季高于秋、冬季. 通过对 所有丽娃河与曹杨环浜样点上、下层沉积物中各种形态磷的含量进行分析发现, 沉积物上层中 Ex-P 与 Or-P 含量明显高于下层含量; 两条河流中除冬季曹杨环浜上层沉积物中 Fe-P 含量低于下层之外, 上层沉积物中 Fe-P的含量均高于下层含量; 对每个样点上、下层沉积物中 OcP 含量进行比较, 丽娃河上层沉积物 OcP 含量 要高于下层, 曹杨环浜上、下层沉积物中 OcP 含量差异不显著. 对比两条河流沉积物各形态磷的含量, 结果 显示: 曹杨环浜上、下层沉积物 Ex-P、Al-P 和 Fe-P 含量都显著低于丽娃河; 曹杨环浜沉积物中Ca-P含量的比 例为 $72.67 \%$ (上层) 和 $74.25 \%$ (下层), 显著高于丽娃河上层沉积物中的 $53.83 \%$ 和下层的 $45.15 \%$; 丽娃 河上、下层沉积物中 OcP 含量所占比例均显著高于曹杨环浜; 曹杨环浜沉积物中 Or-P 含量高于丽娃河 (表 2).

2.2.2 植物生长对沉积物中 Fe-P 含量的影响 在取样调查过程中, 2009 年夏初, 曹杨环浜部分样点附近的 水生植物被河道管理部门人为清除 (水生植被恢复的重要步骤, 在水生植物生物量较大时对植物进行收 割). 对比 2009 年夏末的取样分析结果, 发现在被人为清除水生植物的样点, 上、下层沉积物中 Fe-P 的含量 分别为 9.83 和 $8.64 \mathrm{mg} / \mathrm{kg}$, 显著低于水生植物正常生长样点沉积物 $\mathrm{Fe}-\mathrm{P}$ 的含量. 有植物生长的样点上层沉 积物中 Fe-P 含量平均达到 $64.70 \mathrm{mg} / \mathrm{kg}$, 下层沉积物中 Fe-P 含量为 $28.40 \mathrm{mg} / \mathrm{kg}$. 对比丽娃河夏季和冬季沉 积物中的 Fe-P 含量还发现, 冬季丽娃河上层沉积物中的 Fe-P 含量为 $80.54 \mathrm{mg} / \mathrm{kg}$, 明显低于夏季的 139.57 


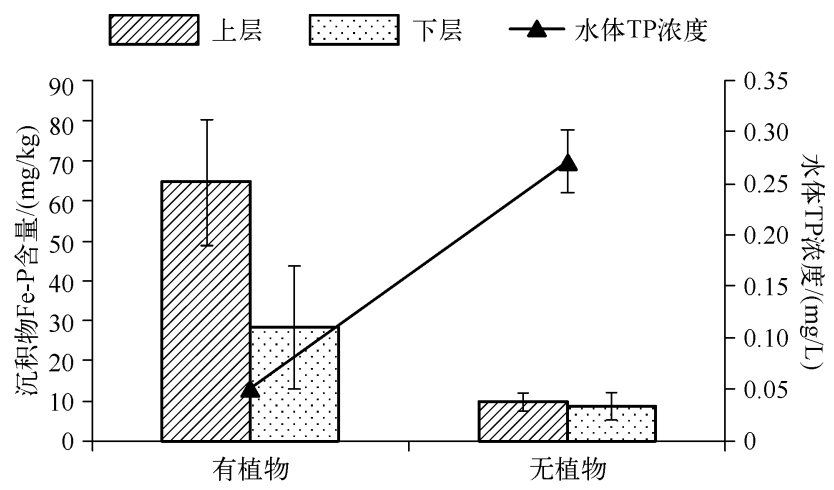

图 2 水生植物对沉积物 Fe-P 和水体 TP 的影响

Fig. 2 Effect of hydrophyte growth on Fe-P in sediment and TP in water

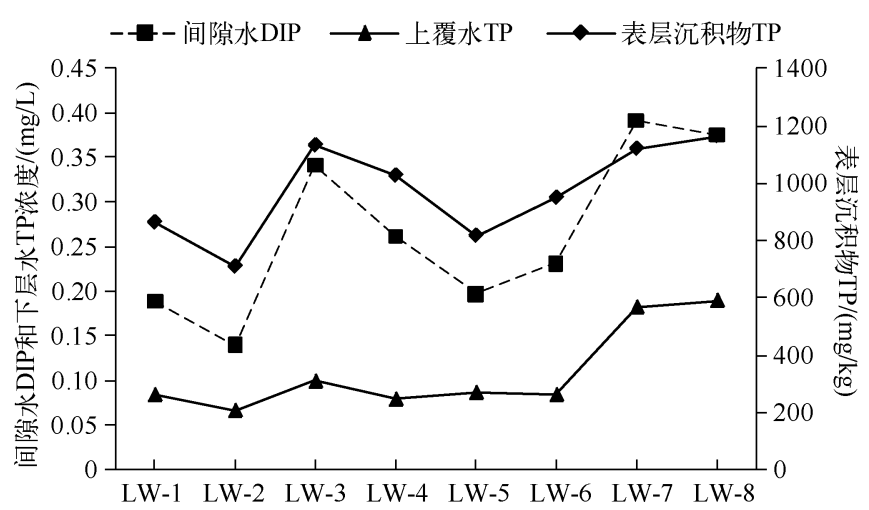

图 3 冬季丽娃河各样点表层沉积物 TP、间隙水 DIP 及下层水 TP 的关系

Fig. 3 Relationships of TP in surface sediment, DIP in interstitial and TP in overlying water in Liwa River in winter $\mathrm{mg} / \mathrm{kg}$, 此时水生植物大都死亡. 这说 明,水生植物生长能够明显增加沉积 物中的 Fe-P 含量, 并且, 在水生植物 根系活动活跃的上层沉积物中 Fe-P 含量的增加更为显著 (图 2).

与之相对应, 在有植物生长的区 域,水体中 TP 浓度 $(0.051 \mathrm{mg} / \mathrm{L})$ 也 显著低于没有植物生长的区域 $(0.272 \mathrm{mg} / \mathrm{L})$.

\section{3 沉积物与水体中磷浓度的关系}

对冬季丽娃河各样点表层沉积 物 TP、对应样点沉积物间隙水 DIP 及 上覆水 TP 浓度进行分析比较发现, 表层沉积物中 TP 含量越高, 对应的 沉积物间隙水 DIP 和上覆水 TP 的浓 度也越高, 且三者在 0.01 水平上极显 著相关(图 3). 这说明, 较高的沉积物 磷负荷是引起水体磷浓度升高的重要 原因. 同时,通过这三者之间的浓度差 异和相关性可以知道, 沉积物中磷的 释放过程是 “沉积物 $\rightarrow$ 间隙水 $\rightarrow$ 上 覆水”.

通过对所有样点沉积物不同形态 磷的含量和水体 TP 浓度进行相关性 分析 (图 4) 发现, 沉积物中 Ex-P 含量 与水体中 $\mathrm{TP}$ 浓度呈极显著负相关 $(r=-0.280, P=0.003)$; Al-P 含量 与水体中 $\mathrm{TP}$ 浓度呈显著负相关 $(r=-0.223, P=0.022)$. 随着季节变 化, Ex-P 与 Al-P 含量变化会引起水体 磷浓度的波动.
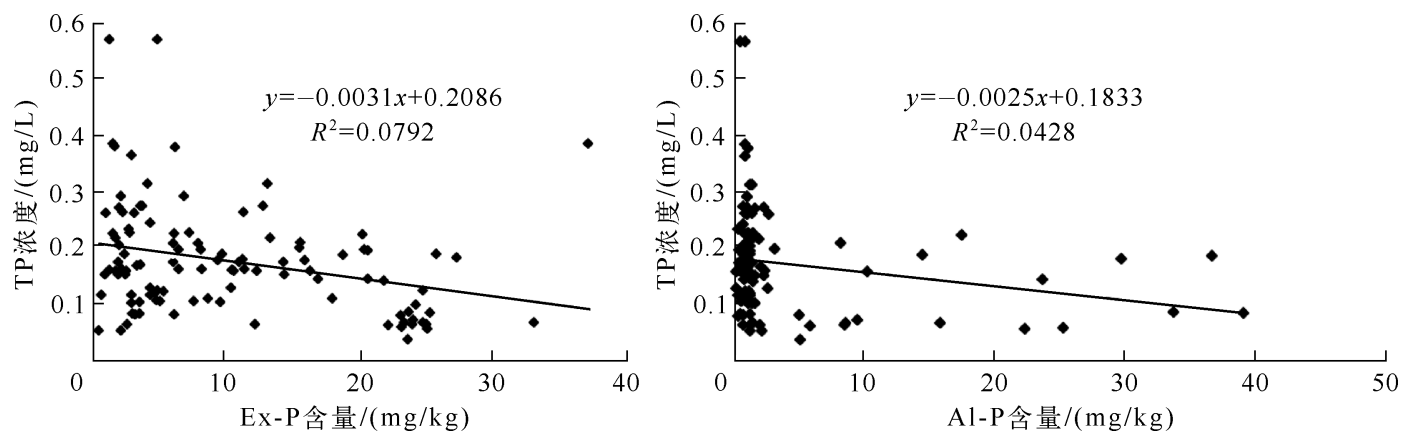

图 4 沉积物中 Ex-P、Al-P 含量与水体中 TP 浓度的相关性

Fig. 4 Correlations of Ex-P, Al-P in sediment with TP in water 


\section{3 讨论}

\section{1 沉积物中磷的形态对水体磷浓度的影响}

在外源污染物的输人得到有效控制之后, 沉积物中内源磷的释放是影响水体富营养化水平的重要原 因 ${ }^{[15]}$. 研究结果表明, 水体 TP 浓度与沉积物 TP 含量显著相关, 沉积物中磷负荷是影响水体磷浓度的重要原 因. 而大量研究表明, 沉积物中磷释放特征是由磷形态组成决定的, 可释放的磷形态是判定磷内源负荷大小 的主要因子 ${ }^{[16-20]}$. 因此, 沉积物中活性磷含量决定沉积物磷的稳定性, 进而影响水中磷浓度. Ex-P、Al-P 和 $\mathrm{Fe}-\mathrm{P}$ 是沉积物中最活跃的几种磷形态, 容易在水体和沉积物之间进行迁移转化, 同时也容易被生物利用, 因 此也被称作 “活性磷” ${ }^{221]}$. Ex-P 主要是吸附在沉积物表面的磷, 很容易受到沉积物理化性质如温度、pH、水 动力条件和生物扰动等因素的影响, 在水体和沉积物之间迁移 ${ }^{[22]}$. 本研究中, 上层沉积物中 Ex-P 和 Al-P 含 量随季节变化明显 (图 5). 秋、冬季节, 丽娃河沉积物中的 Ex-P 和 Al-P 含量逐渐增加, 在冬季达到最大值, 分别为 24.95 和 $12.51 \mathrm{mg} / \mathrm{kg}$; 春、夏季节, 沉积物中 Ex-P 和 Al-P 的含量持续下降, 其中 Ex-P 在夏季达到最 低值 $7.14 \mathrm{mg} / \mathrm{kg}$, 呈现明显的季节变 化规律. 与沉积物中 Ex-P 和 Al-P 含 量的季节变化相对应, 丽娃河水体的 磷浓度变化恰好相反, TP 浓度在秋、 冬季节呈下降趋势, 而在春、夏季节浓 度升高, 水体 TP 和 DIP 浓度在夏季达 到最高值. 因此, 可以说明, 水体磷浓 度的季节变化最主要是受到沉积物中 的活性磷, 特别是 Ex-P 和 Al-P 释放 的影响: 秋、冬季节, 随着温度下降, 水 体中的活性磷开始向沉积物沉降, 同 时植物残体逐渐分解沉降到沉积物 中, 沉积物成为磷的汇 ${ }^{[23-24]}$, 水体 TP 和 DIP 的浓度下降而沉积物中活性磷

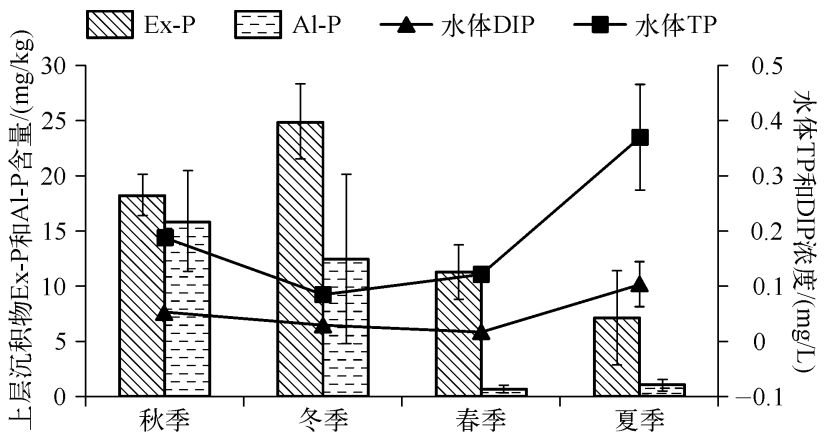

图 5 丽娃河上层沉积物中 Ex-P 和 Al-P 的含量 及水体 TP 和 DIP 浓度的季节变化

Fig. 5 Seasonal variations of Ex-P, Al-P in surface sediments and TP, DIP in water in Liwa River 的含量增加; 春、夏季节, 在高温情况

下沉积物磷的释放加剧, 加上降水的增加和植物生长等因素的扰动作用, 沉积物变成磷的源, 沉积物中的磷 向水体释放,从而使水体中 TP 与 DIP 浓度明显升高.

\section{2 植物生长对沉积物磷形态和水体磷浓度的影响}

水生植物生长能够明显改善水质, 同时通过一系列生物化学过程, 影响沉积物中磷的形态 ${ }^{[25-26]} . \mathrm{Fe}-\mathrm{P}$ 是 以与铁的氧化物或氢氧化物结合形式存在的磷, 具有较强的生物活性, 易受到沉积物氧化还原条件的影 响 ${ }^{[27]}$. 本研究中, 水生植物被人为清除后的样点, 沉积物中 Fe-P 含量显著低于水生植物正常生长的样点, 而 对应的没有植物的样点上覆水中 TP 浓度却显著高于植物正常生长的点. 这是由于在水生植物生长过程中, 通气组织以及植物的根际泌氧, 会使得植物根际的沉积物处于氧化环境. 在氧化条件下, 沉积物中的 $\mathrm{Fe}^{2+}$ 氧 化生成 $\mathrm{Fe}^{3+}$, 与水体和沉积物间隙水中的磷酸盐结合生成难容的 $\mathrm{Fe}-\mathrm{P}$ 固定在沉积物中 ${ }^{[28]}$, 从而降低了水体 磷浓度.

水生植物的生长能够大量吸收富集水体和沉积物中的营养元素 ${ }^{[29-31]}$. Knight 等 $^{[32]}$ 在北美佛罗里达州对 13 个河湖湿地系统的研究发现, 沉水植物能够长期有效地去除水体中的磷, 去除能力高达 $120 \mathrm{~kg} /\left(\mathrm{hm}^{2} \cdot \mathrm{a}\right)$. 本研究中, 春季两条河流水体中 DIP 浓度变化也证明了这一点: 春季升温时, 沉积物中的 磷向水体中释放,引起水体 TP 浓度增加, 而水体中的 DIP 的浓度不仅没有随温度升高而增加, 反而呈现下 降趋势, 这是由于春季水生植物开始大量生长, 大量吸收利用可溶性无机磷所致. 水生植物吸收了磷元素之 后, 对其进行收割, 能够有效降低和控制水体 P 的浓度, 同时也能将沉积物中的磷通过植物体的吸收从城市 水体中迁移出来, 从而降低城市水体沉积物中内源性磷的负荷. 


\section{3 水生植被恢复时间长短对沉积物磷形态及水体磷浓度的影响}

两条水体富营养化状况相似的城市河流, 在经过不同时间的水生植被恢复后, 沉积物中磷的总量和磷 形态组成分布都发生了明显的改变. 通过对比发现, 恢复时间更长的曹杨环浜沉积物中 Ex-P、Al-P 和 Fe-P 含量都显著低于丽娃河. 有研究表明, 沉积物中的 Fe-P 为磷的 “中转站” 而并非归属 ${ }^{[33]}$. 虽然短期内水生植 物生长改变了根际沉积物的氧化还原条件, 促进了水体中的磷与 $\mathrm{Fe}^{3+}$ 结合生成 $\mathrm{Fe}-\mathrm{P}$, 但 $\mathrm{Fe}-\mathrm{P}$ 也具有较强的 生物活性, 作为磷的中间形态会通过一系列生物化学作用转化为其他形态的磷. 并且, 随着水生植被恢复时 间的增加, 曹杨环浜沉积物中的活性磷 Ex-P 和 Al-P 的含量也都显著低于丽娃河. 随着水生植被恢复时间的 增加, 物种构成更加复杂, 水生生态系统更加趋于稳定, 其中复杂的生态过程使活性磷进人生态系统, 被生 物利用或者向其他更稳定的磷形态转化, 从而降低了沉积物中活性磷 Ex-P、Al-P 和 Fe-P 的含量.

为比较水生植被恢复时间长短对河流产生的影响, 将两条河流沉积物各形态磷的含量和比例进行对 比, 研究发现曹杨环浜上层沉积物中的 Ca-P 所占比例为 $72.67 \%$, 显著高于丽娃河上层沉积物的 Ca-P 含量 $(53.83 \%)$. 这说明, 随着水生植被恢复时间的增加, 沉积物中 Ca-P 的比例在逐渐升高. 沉积物中 Ca-P 主要 以自生磷灰石 (authigenic carbonate fluorapatite)、生物磷灰石 (biogenic apatite) 以及碳酸钙结合 $\left(\mathrm{CaCO}_{3}\right.$-associated P) 的形式存在 ${ }^{[34]}$. 其中生物磷灰石也被称为生物碎屑磷, 主要是鱼类、贝类、螺类等水生动物死亡后 骨骼、贝壳等残体的含磷矿物引人的 Ca- $\mathrm{P}^{[35]}$. 水生植物的生长能有效增加空间生态位, 提高水生生态系统 中底栖动物、浮游植物等水生生物的物种多样性 ${ }^{[36-38]}$. 经过长期的水生植被恢复, 曹杨环浜的水生生态系统 更加稳定, 生物多样性更复杂, 鱼类、螺类等生物比丽娃河更为丰富, 死亡后残体中的含钙矿物导致生物磷 灰石的 Ca-P 含量增加, Ca-P 在沉积物中比例上升, “活性磷” 转化为相对稳定的 Ca-P. 因此, Ca-P 的变化可 能是判断水生植被恢复水生态效应的较好指标.

$\mathrm{OcP}$ 是指被氧化铁胶膜包被的磷酸盐, 这种形态的磷很难释放出来被作物吸收利用. 但本研究中, 恢复 时间更长的曹杨环浜上、下层沉积物中 $\mathrm{OcP}$ 含量都显著高于恢复时间相对较短的丽娃河; 并且, 在丽娃河 中, 植物根系生长活跃的上层沉积物中 OcP 含量也高于下层沉积物. 有研究表明, 当用还原一络合技术除去 外表氧化铁膜后, 在碱性条件下几乎所有的蓄闭态磷都可以被提取出来 ${ }^{[12]}$. 因此, OcP 应该被称作还原态可 溶磷酸盐 (reductant soluble phosphate) $)^{[39]}$. 周小宁等 ${ }^{[40]}$ 还发现沉水植物黑藻对沉积物磷有活化作用, 会增加 沉积物中潜在可交换磷的量, 植物的根系分泌物释放到沉积物中, 会改变沉积物的理化特性和生物反应, 如 $\mathrm{pH}$ 、氧化还原电位和表面结构、微生物数量及活性等, 同时某些分泌物及植物残体有机质可作为良好的络合 剂, 很可能在还原条件下将 $\mathrm{OcP}$ 释放出来. 水生植物通过光合作用消耗水体中的 $\mathrm{CO}_{2}$, 会增加水体和沉积物 的 $\mathrm{pH}$ 值. 有研究表明, 沉水植物的生长对水体 $\mathrm{pH}$ 有很大的影响, 伊乐藻的生长可以使水体 $\mathrm{pH}$ 从初始的 7.5 上升至 8.6 以上 ${ }^{[41]}$. 通过对比曹杨环浜和丽娃河 2009 年水体的 $\mathrm{pH}$ 值也发现, 水生植被恢复时间更长的 曹杨环浜, 水体 $\mathrm{pH}$ 值 (8.40) 显著大于恢复时间相对较短的丽娃河 (7.78). 水生植被恢复增加了水体和沉 积物的 $\mathrm{pH}$, 同时长期的水生植被恢复向沉积物中释放了大量的根际分泌物, 活化沉积物中的磷以及分泌物 和植物残体有机质为沉积物提供了有机络合剂, 经过长期的生物化学作用, 这些很难被利用的磷形态很可 能转化为生物可利用的磷形态而被水生植物所利用. 曹杨环浜上层沉积物 Or-P 含量明显高于丽娃河, 经过 长期的水生植被恢复, 水生生态系统更加复杂和稳定, 植物残体有机质向沉积物的沉降, 增加了上层沉积物 中 Or-P 的含量, 曹杨环浜表层沉积物中较高的 Or-P 含量也为 OcP 的活化提供了可能.

长期的水生植被恢复使水生生态系统趋于稳定, 水生生物物种更加丰富, 食物链更加复杂, 从而使更多 的营养元素磷停留在食物链中. 同时, 定期的管理和植物收割将吸收富集大量磷元素的水生植物从城市水 体中移除, 能够有效降低和控制水体磷浓度, 并将沉积物中的磷通过植物体的吸收从城市水体中迁移出来, 从而降低城市水体沉积物中内源性磷的负荷. 这也是没有进行底泥疏浚的曹杨环浜的沉积物磷负荷低于清 淤的丽娃河的最主要原因.

沉积物和水体磷的季节变化规律也证明了温度是影响沉积物中的磷向水体中释放的重要因素之一, 随 着温度的升高, 沉积物释放的磷含量会逐渐增多 ${ }^{[42-43]}$. 曹杨环浜各季节的水体温度比丽娃河低 $2^{\circ} \mathrm{C}$ 左右. 这 可能是因为经过了长期的水生植被恢复, 曹杨环浜的水生生态系统和水体周围的生境更加稳定, 较高的水 生植物的盖度和周围景观树木的郁闭度能够避免阳光直射, 从而导致曹杨环浜的水温比修复时间相对较短 
的丽娃河低. 较低的水温也是曹杨环浜水体磷浓度低于丽娃河的原因之一.

研究结果表明, 长期的水生植被恢复能够降低沉积物中活性磷的比例, 使沉积物中的磷变得更加稳定, 减少沉积物中磷的释放, 同时长期的水生植被恢复和定期植物收割能够有效降低城市水体沉积物内源性的 磷负荷, 从而降低城市水体中磷的浓度. 研究结果还表明,水生植被恢复对水体氮的浓度也有显著的控制作 用, 特别是水体 $\mathrm{NH}_{4}^{+}-\mathrm{N}$ 的浓度, 随着水生植被恢复时间的增加, 水体 $\mathrm{NH}_{4}^{+}-\mathrm{N}$ 的浓度显著下降. 同时, 水生植 被恢复能够明显增加水体的溶解氧. 这说明, 水生植被恢复是控制和治理城市水体富营养化的有效措施, 能 够长期有效地改善城市景观水体水质.

\section{4 结论}

利用水生植物构建水生生态系统对富营养化水体进行修复, 对水体和沉积物中磷的影响主要体现在短 期生态效应和长期生态效应两个方面:

水生植被恢复的短期生态效应: 首先, 水生植物可以直接从水体与沉积物中吸收氮、磷等营养物质, 对 水体磷尤其是 DIP 有明显的吸收作用. 其次, 水生植物生长季节根际泌氧作用促进根际水体中的磷与 $\mathrm{Fe}^{3+}$ 结合生成 Fe-P 并向沉积物中沉降, 降低水体中磷的浓度.

水生植被恢复的长期生态效应则表现为:

1) 长期的水生植被恢复能够长期有效地控制和降低水体中 $\mathrm{N} 、 \mathrm{P}$ 等营养元素的浓度, 增加水体溶解氧, 并且能够增强水质在季节交替和升温等自然条件改变时的稳定性,对富营养化水体作用显著.

2) 长期的水生植被恢复可使沉积物中 Fe-P、Al-P 以及 Ex-P 等活性磷的比例降低, 对 Ex-P 和 Fe-P 的作 用尤为明显.

3) 长期水生植被恢复增加了相对稳定的 Ca-P 含量, 对水生生态系统结构和功能的恢复有重要作用, 能 有效增加水生生态系统中生物多样性与生物量, 鱼类、螺类等生物残体的累积使沉积物中不易释放的 Ca-P 比例上升,利于对富营养化水体沉积物磷素释放的控制.

4) 通过水生植物的生长, 活化和吸收沉积物中的磷, 再通过对水生植物的人为收割, 降低沉积物中磷的 浓度, 从而降低沉积物内源性磷负荷.

\section{5 参考文献}

[ 1 ] 宋永昌,戚仁海, 由文辉等. 生态城市的指标体系与评价方法. 城市环境与城市生态, 1999,12(5):16-19.

[ 2 ] Sas H. Lake restoration by reduction of nutrient loading: expectations, experiences and extrapolations. St Augustin, Germany: AcedemiaVerlag, 1989.

[ 3 ] Rydin E. Potentially mobile phosphorus in lake Erken sediment. Water Research, 2000, 34 (7) : 2037-2042.

[ 4 ] Phillips GL, Eminson D, Moss B. A mechanism to account for macrophyte decline in progressively eutrophicated freshwaters. Aquatic Botany, 1978, 4: 103-126.

[ 5 ] Stefanidis K, Papastergiadou E. Influence of hydrophyte abundance on the spatial distribution of zooplankton in selected lakes in Greece. Hydrobiologia, 2010, 656 (1) : 55-65.

[ 6 ] Tang X, Wu M, Yang W et al. Ecological strategy for eutrophication control. Water, Air, and Soil Pollution, 2012, 223 (2) : 723-737.

[ 7 ] 吴振斌, 邱东茹,贺 锋等. 沉水植物重建对富营养水体氮磷营养水平的影响. 应用生态学报, 2003,14 (8): 1351-1353.

[ 8 ] 成小英,王国祥, 誉培民等. 冬季富营养化湖泊中水生植物的恢复及净化作用. 湖泊科学, 2002,14(2): 139-144.

[ 9 ] 全为民, 沈新强, 严力蛟. 富营养化水体生物净化效应的研究进展. 应用生态学报, 2003,14 (11):2057-2061.

[10］黄民生,徐亚同,陈邦林等. 丽娃河环境治理与生态恢复工程. 净水技术,2005,24(6):56-59.

[11] 王春树, 胡险峰, 杜晓舜. 生态工程技术在城市河道治理中的应用研究. 水利发展研究, 2005,7:21-23.

[12] 金相灿,屠清瑛. 湖泊富营养化调查规范:第 2 版. 北京: 中国环境科学出版社, 1990.

[13] 国家环境保护总局《水和废水监测分析方法》编委会. 水和废水监测分析方法: 第 4 版. 北京: 中国环境科学出版 社, 2002 .

[14] 李静文, 施 文, 余丽凡等. 丽娃河受损退化生态系统的近自然恢复工程及效果分析. 华东师范大学学报: 自然科 学版, 2010, (4) :35-43. 
[15] 齐孟文,刘风娟. 城市水体富营养化的生态危害及其防治措施. 环境科学动态, 2004, (1):44-46.

[16] Zhou Y, Song C, Cao X et al. Phosphorus fractions and alkaline phosphatase activity in sediments of a large eutrophic Chinese lake (Lake Taihu). Hydrobiologia, 2008, 599(1) : 119-125.

[17] Huang QH, Wang ZJ, Wang DH et al. Origins and mobility of phosphorus forms in the sediments of Lakes Taihu and Chaohu, China. Journal of Environmental Science and Health, 2005, 40(1) : 91-102.

[18] Liu C, Sui JY, Wang ZY. Sediment load reduction in Chinese rivers. International Journal of Sediment Research, 2008, $23(1)$ : 44-55.

[19] Kaiserli A, Voutsa D, Samara C. Phosphorus fractionation in lake sediments-Lakes Volvi and Koronia, N. Greece. Chemosphere, 2002, 46(8): 1147-1155.

[20] Zhou Q, Gibson CE, Zhu Y. Evaluation of phosphorus bioavailability in sediments of three contrasting lakes in China and the UK. Chemosphere, 2001, 42(2): 221-225.

[21] 朱广伟, 秦伯强, 高 光等. 长江中下游浅水湖泊沉积物中磷的形态及其与水相磷的关系. 环境科学学报, 2004,24 (3) :381-388.

[22] 戴继翠, 宋金明,李学刚等. 胶州湾沉积物中的磷及其环境指示意义. 环境科学, 2006,27(10):1953-1962.

[23] 范成新,张 路, 秦伯强等. 太湖沉积物一水界面生源要素迁移机制及定量化. 湖泊科学, 2004,16(1):10-20.

[24] 许薇薇, 袁旭音, 黄小荣. 南通通吕运河沉积物营养元素及重金属的季节性特征研究. 长江流域资源与环境, 2009, 18 (7):674-679.

[25] 王立志, 王国祥, 俞振飞等. 苦草(Vallisneria natans) 生长期对沉积物磷形态及迁移的影响. 湖泊科学,2011,23(5): $753-760$.

[26] 包先明,陈开宁, 范成新. 种植沉水植物对富营养化水体沉积物中磷形态的影响. 土壤通报,2006,37(4):710-715.

[27] 章婷瞳, 王晓蓉, 金相灿. 太湖不同营养水平湖区沉积物中磷形态的分布特征. 农业环境科学学报,2007,26(4): 1207-1213.

[28] 姜敬龙,吴云海. 底泥磷释放的影响因素. 环境科学与管理, 2008,33(6) :43-46.

[29] Rattray MR, Howard-Williams C, Brown JMA. Sediment and water as sources of nitrogen and phosphorus for submerged rooted aquatic macrophytes. Aquatic Botany, 1991, 40(3) : 225-237.

[30] Anderson MR, Kalff J. Submerged aquatic macrophyte biomass in relation to sediment characteristics in ten temperate lakes. Freshwater Biology, 1988, 19(1): 115-121.

[31] 黄 亮, 吴乃成,唐 涛等. 水生植物对富营养化水系统中氮、磷的富集与转移. 中国环境科学, 2010,30(Suppl. ) : $1-6$.

[32] Knight RL, Gu B, Clarke RA et al. Long-term phosphorus removal in Florida aquatic systems dominated by submerged aquatic vegetation. Ecological Engineering, 2003, 20(1) : 45-63.

[33] 徐会玲,唐志勇, 朱端卫等. 埧草一伊乐藻对沉积物磷形态及其上覆水水质的影响. 湖泊科学, 2010,22 (3): 437-444.

[34] Rutenberh KC. Development of a sequential extraction method for different forms of phosphorus in marine sediments. Limnology and Oceanography, 1992, 37(7):1460-1482.

[35] 朱广伟, 高 光, 秦伯强等. 浅水湖泊沉积物中磷的地球化学特征. 水科学进展, 2003,14(6):714-719.

[36] Scheffer M, van den Berg M, Breukelaar A et al. Vegetated areas with clear water in turbid shallow lakes. Aquatic Botany, 1994, 49(2): 193-196.

[37] Pokorny J, Kvet J, Ondok JP. Functioning of the plant component in densely stocked fishponds. Bulletin d'Ecologie, $1990,21(3): 44-48$.

[38] 高亚岳, 周 俊,陈志宁等. 滆湖富营养化进程中沉水植被的演替及重建设想. 江苏环境科技,2008,21 (4):21-24.

[39] Chang SC, Jackson ML. Fractionation of soil phosphorus. Soil Science, 1957, 84(2) : 133-144.

[40] 周小宁, 王圣瑞, 金相灿. 沉水植物黑藻对沉积物有机、无机磷形态及潜在可交换性磷的影响. 环境科学,2006,27 (12) :2421-2425.

[41] 赵联芳,朱 伟, 莫妙兴. 沉水植物对水体 $\mathrm{pH}$ 值的影响及其脱氮作用. 水资源保护,2008,24(6):64-67.

[42] 尹大强,覃秋荣, 阎 航. 环境因子对五里湖沉积物磷释放的影响. 湖泊科学, 1994,6(3):240-244.

[43] 韩沙沙,温琰茂. 富营养化水体沉积物中磷的释放及其影响因素. 生态学杂志, 2004,23(2):98-101. 